Volume 8, No.6, November - December 2019

International Journal of Advanced Trends in Computer Science and Engineering

Available Online at http://www.warse.org/IJATCSE/static/pdf/file/ijatcse67862019.pdf

https://doi.org/10.30534/ijatcse/2019/67862019

\title{
Model for representation the relations between geometric objects and Drawing a figure of the problem in Plane geometry
}

\author{
Hien D. Nguyen ${ }^{1}$, Khang Le ${ }^{2}$, Phong T. Luc ${ }^{3}$, Minh N. Phan ${ }^{4}$, Vuong T. Pham ${ }^{5}$ \\ ${ }^{1}$ University of Information Technology, VNU-HCM, Vietnam, Email: hiennd@uit.edu.vn \\ ${ }^{2}$ University of Information Technology, VNU-HCM, Vietnam, Email: levogiakhang@ gmail.com \\ ${ }^{3}$ University of Information Technology, VNU-HCM, Vietnam, Email: luctruongphong13@gmail.com \\ ${ }^{4}$ University of Information Technology, VNU-HCM, Vietnam, Email: minhpn@uit.edu.vn \\ ${ }^{5}$ Sai Gon University, Vietnam, Email: vuong.pham@sgu.edu.vn
}

\begin{abstract}
When building the Intelligent Problem Solver (IPS) in plane geometry, the figure of a problem is very important. Though the figure, the hypothesis can be specified adequately and visually. When solving a problem, the figure helps to imagine and grasp the important information from the problem. In this paper, based on the knowledge base of plane geometry which was built by Rela-model, the relational network between geometric objects in a problem is proposed. Using this network, algorithms for automatically drawing the figure of a geometric problem are designed. The program for automatically drawing the figure is designed and tested for mathematical exercises in middle-school. This program is useful to support the problem-solving in plane geometry.
\end{abstract}

Key words: Knowledge representation; intelligent problem solver; knowledge of relations; relational network; automatic drawing.

\section{INTRODUCTION}

Intelligent Problem Solver (IPS) is a kind of intelligent learning system. In an IPS, the problems will be represented by specification language and this system can solve many kinds of the problems in the curriculum of the knowledge domain. The knowledge base of an IPS system should be adequate to solve problems in the certain knowledge domain and their specification language was similar to that of human [1]. Besides, the solutions of this system are step-by-step, readable and suitable with the learners' level.

When building the IPS in plane geometry, the figure of a problem is very important. The figure makes the learner being able to observer the problem visually. Though the figure, the hypothesis can be specified adequately. When solving a problem, the figure helps to imagine and grasp the important information from the problem. Drawing the figure is also a method to realize the facts in the hypothesis more clearly and quickly. From that, an IPS in plane geometry with the illustrate figure meets the requirements of an IPS in education $[4,16]$.
In [2, 3], the authors present an Intelligent Problem Solver for solving exercises in plane geometry at middle school. Although the system could give step-by-step solutions, it did not have the figure to illustrate the problem.

In this paper, the knowledge model of relations, Rela-model $[3,5]$, is applied to represent the knowledge base of plane geometry. Based on the structure of this knowledge base and the semantic network [6], the relational network between geometric objects in a problem is proposed. Using the improved relational network, algorithms for automatically drawing the figure of a problem are designed. Based on those results, a program for automatically drawing the figure of a geometric problem are built. This program is useful to support the problem-solving in plane geometry.

The next section analyses some related works for drawing of the figure of plane geometry. Section 3 presents the knowledge base of plane geometry using the knowledge model of relations. This section also proposes the relational network to represent the relations between geometric objects. Section 4 presents the problems about automatic drawing a figure of plane geometry, and designs of algorithms for solving them. There are two problems for solving it: Building the relational network between geometric objects, and drawing the figure of an exercise. Based on the proposed knowledge model and algorithms, a program for a program for drawing the figure of geometric exercises has been set up and tested in section 5. The last section concludes the paper and gives some future works.

\section{RELATED WORK}

Nowadays there are many programs can support the drawing of the figure for geometric problems, but it still has the limitations for building the IPS in plane geometry.

GeoGebra is an interactive geometry intended for learning and teaching mathematics [9]. The program can draw some basic geometric objects: Point, Segment, Line, Circle. Besides, in $[10,11]$, GeoGebra is also used as an automatic reasoning 
tool for automatic finding of geometric conjectures and the verification or denial of these conjectures through the Relation command. However, it only can draw a figure manually, it cannot product the figure automatically from the hypothesis of the problem.

The Geometer's Sketchpad is a commercial interactive geometry software program for exploring Euclidean geometry $[12,13]$. It can construct the figure alike the drawing with the compass and straightedge method. Nonetheless, this program only can draw a figure manually.

The program in [7] uses the relational network between geometric objects to draw the figure of the problem automatically. However, its specification language is too simple, so it only can execute each object discretely, it cannot process based on the hypothesis of the problem.

The study of this paper proposes a model to represent the relational network between geometric objects in a problem based on the combination between the knowledge model of relations and the conceptual graph. The structure of this network is improved from [7] to represent objects and their relationships more clearly and exactly. This approach is carried out based on a logic pattern in terms of semantic relation between objects [8]. This network is the foundation to design of algorithms for drawing the figure of plane geometry automatically.

\section{KNOWLEDGE BASE OF PLANE GEOMETRY}

\subsection{Knowledge base}

\section{A. Rela-model and model of problems}

The Rela-model is an effective model to represent the knowledge of relations [5]. This model was applied to represent knowledge domains about plane geometry [3] and solid geometry [14]. In this section, Rela-model is used to represent the relations between geometric objects in the figure.

Definition 3.1 [5]: The knowledge model of relations, called Real-model, is a tube:

\section{(C, R, Rules)}

In which:

(1) $\mathbf{C}$ is a finite set of concepts. Each concept $\mathrm{c}$ is a class of objects and has an instance set, called $\mathrm{I}_{\mathrm{c}}$. Concept $\mathrm{c}$ is a triple (Attrs, Facts, RulObj), which Attrs is a set of attributes, Facts is a set of facts of concepts, and RulObj is a set of deductive rules of concept.

(2) $\mathbf{R}$ is a finite set of binary relations between concepts in C.

(3) Rules is a set of inference rules of the knowledge domain. Each rule $r \in$ Rules has the form: $u(r) \rightarrow v(r)$, where $u(r), v(r)$ are set of facts.
Definition 3.2: Let $K=(\mathbf{C}, \mathbf{R}$, Rules $)$ be a knowledge model of relations as Rela-model. The model of a problem on $\mathrm{K}$ is:

$$
(\mathbf{O}, \mathbf{F}) \rightarrow \text { Goal }
$$

In which: $\mathbf{O}=\left\{\mathrm{O}_{1}, \mathrm{O}_{2} \ldots, \mathrm{O}_{\mathrm{m}}\right\}$, the set of objects in the problem.

$$
\begin{aligned}
& \mathbf{F}=\left\{\mathrm{f}_{1}, \mathrm{f}_{2}, \ldots, \mathrm{f}_{\mathrm{n}}\right\}, \text { the set of facts } \\
& \text { Goal }=\left\{\mathrm{g}_{1}, \mathrm{~g}_{2}, \ldots, \mathrm{g}_{\mathrm{k}}\right\}, \text { the goal of the problem. }
\end{aligned}
$$

Each $\mathrm{g}_{\mathrm{i}} \in \mathbf{G o a l}$ is: Determine an object, or Consider a relation between objects.

\section{B. Knowledge base of plane geometry}

The knowledge of plane geometry, which has been mentioned in [14], can be represented by the Rela-model [3].

\section{(C, R, Rules)}

1) $\mathbf{C}-$ set of concepts: Set $\mathbf{C}$ consists of concepts, such as:

$$
\mathbf{C}=\mathrm{C}_{(0)} \cup \mathrm{C}_{(1)}
$$

$\mathrm{C}_{(0)}=\{\nabla$, POINT, LINE $\} \quad / / \nabla$ : set of real numbers.

$\mathrm{C}_{(1)}=\{$ SEGMENT, RAY $\}$

Concept SEGMENT $\in \mathrm{C}_{(1)}$ has structure:

Attrs $=\left\{\_\mathrm{A}, \_\mathrm{B}\right.$, len $\}$, which:

$$
\text { _A, _B: POINT }
$$

len: $\nabla$;

Facts $=\{$ len $>0\}$

$$
\text { RulObj }=\{\}
$$

$\mathrm{C}_{(2)}=$ \{ANGLE, TRIANGLE and types of it, QUADRANGLE and types of it, CIRCLE, ... $\}$

Concept PARALLELOGRAM $\in \mathrm{C}_{(2)}$ consists of:

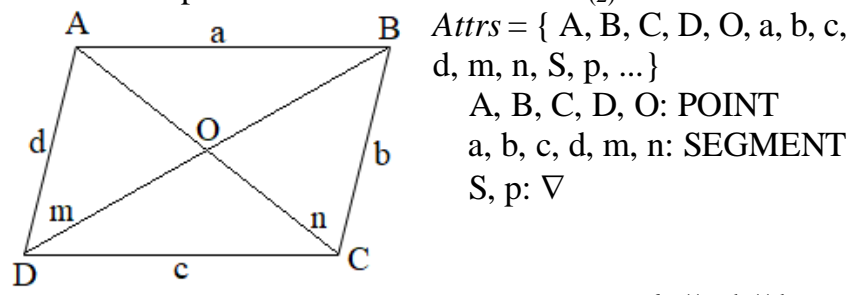

$\mathrm{c}, \mathrm{b}=\mathrm{d}, \mathrm{O}=\mathrm{m}$ intersect $\mathrm{n}$,

Facts $=\{\mathrm{a} / / \mathrm{c}, \mathrm{b} / / \mathrm{d}, \mathrm{a}=$

OA midpoint AC, $\mathrm{O}$ midpoint $\mathrm{BD}\}$

$$
\begin{aligned}
\text { RulesObj }= & \left\{\mathrm{r}_{1}:\{\mathrm{m} \perp \mathrm{n}\} \rightarrow\{\text { this: ROHMBUS }\},\right. \\
& \mathrm{r}_{2}:\{\mathrm{m}=\mathrm{n}\} \rightarrow\{\text { this: RECTANGLE }\}, \\
& \mathrm{r}_{3}:\{\mathrm{a}=\mathrm{b}\} \rightarrow\{\text { this: ROHMBUS }\},
\end{aligned}
$$$$
\mathrm{r}_{4}:\{\angle \mathrm{BOD} \quad=\quad \mathrm{Pi} / 2\} \rightarrow \quad\{\text { this: }
$$

RECTANGLE\},

$$
\left.\mathrm{r}_{5}:\{\mathrm{m} \perp \mathrm{n}\} \rightarrow\{\mathrm{S}=1 / 2 * \mathrm{~m} * \mathrm{n}\}\right\}
$$

2) $\mathbf{R}-$ set about relations:

There are various kinds of relations between concepts in $\mathbf{C}$

- Relations on $\mathrm{c} \in \mathbf{C}$ : there are binary relations between objects that have the same type, such as:

+ Relation between Congruent triangles

+ Relation between Similar triangles

- Relations on $\mathrm{c}_{\mathrm{i}} \times \mathrm{c}_{\mathrm{j}}\left(\mathrm{c}_{\mathrm{i}}, \mathrm{c}_{\mathrm{j}} \in \mathbf{C}\right)$ : there are binary relations between objects that have different types:

+ Relation on MIDPOINT: between a point and a segment.

+ Relations on PERPENDICULAR $(\perp)$ : between two lines, two segments, a line and a segment, etc. 
+ Relations on PARALLELE (//): between two lines, two segments, a line and a segment, etc.

+ Relations on INTERSECT: between two lines, two segments, a line and a segment, etc.

Besides, some hierarchical relations between concepts in $\mathbf{C}$ are also constructed:

+ Hierarchical relations on class Triangle.

+ Hierarchical relations on class Quadrangle.

3) Rules-set of rules: Some particular rules can be represented by deductive rules:

- $\{$ a: SEGMENT, b: SEGMENT, c: SEGMENT, $\mathrm{a} / / \mathrm{b}, \mathrm{b} \perp \mathrm{c}\}$

$$
\rightarrow\{\mathrm{a} \perp \mathrm{c}\}
$$

- $\{\mathrm{O}$ : POINT, AB: SEGMENT, CD: SEGMENT, $\mathrm{O}=\mathrm{AB}$ intersect $\mathrm{CD}\}$

$$
\rightarrow\{\angle \mathrm{AOC}=\angle \mathrm{BOD}, \angle \mathrm{AOD}=\angle \mathrm{BOC}\} .
$$

- \{DEF: TRIANGLE, P: POINT, Q: POINT, $\mathrm{P}$ midpoint DE, $\mathrm{Q}$ midpoint $\mathrm{DF}\}$ $\rightarrow\{\mathrm{PQ} / / \mathrm{EF}, \mathrm{PQ}=1 / 2 \mathrm{EF}\}$

\section{Kinds of facts}

Let $\mathrm{K}=(\mathbf{C}, \mathbf{R}$, Rules) be a knowledge model of relations as Rela-model. Kinds of facts is classified as Table 1:

\begin{tabular}{|c|c|c|c|}
\hline Kind & Denote & Condition & Example \\
\hline $\begin{array}{l}\text { Kind 1: } \\
\text { Inform the } \\
\text { object kind }\end{array}$ & $\mathrm{x}: \mathrm{c}$ & $\mathrm{x} \in \mathrm{I}_{\mathrm{c}}, \mathrm{c} \in \mathbf{C}$ & $\begin{array}{l}\text { AB: Segment, } \\
\text { d: Line, } \\
\text { T: Triangle }\end{array}$ \\
\hline $\begin{array}{l}\text { Kind 2: } \\
\text { Determine an } \\
\text { object or an } \\
\text { attribute of an } \\
\text { object }\end{array}$ & $\begin{array}{l}\mathrm{x} \\
\mathrm{x} . \mathrm{a}\end{array}$ & $\begin{array}{l}\mathrm{x} \in \mathrm{I}_{\mathrm{c}}(\mathrm{c} \in \mathbf{C}) \\
\mathrm{a} \in \mathrm{x} \cdot \text { Attrs }\end{array}$ & $\begin{array}{l}\text { Triangle }(A B C) \\
\text { T.S (area of triangle T) }\end{array}$ \\
\hline $\begin{array}{l}\text { Kind 3: } \\
\text { Determine an } \\
\text { object by a value } \\
\text { or a constant } \\
\text { expression }\end{array}$ & $\begin{array}{l}\mathrm{x}= \\
<\text { const }>\end{array}$ & $\mathrm{x} \in \mathrm{I}_{\mathrm{c}}(\mathrm{c} \in \mathbf{C})$ & $\begin{array}{l}\mathrm{AB}=5 \\
\text { Angle }(\mathrm{ABC})=\pi / 3\end{array}$ \\
\hline $\begin{array}{l}\text { Kind 4: } \\
\text { Equality on } \\
\text { objects }\end{array}$ & $x=y$ & $\begin{array}{l}\mathrm{x} \in \mathrm{I}_{\mathrm{cx}}, \mathrm{y} \in \mathrm{I}_{\mathrm{cy}} \\
\left(\mathrm{c}_{\mathrm{x}}, \mathrm{c}_{\mathrm{y}} \in \mathbf{C}\right)\end{array}$ & $\begin{array}{l}\mathrm{AB}=\mathrm{AC} \\
\text { Triangle }(\mathrm{ABC})= \\
\text { Triangle }(\mathrm{DEF})\end{array}$ \\
\hline $\begin{array}{l}\text { Kind 5: } \\
\text { A relation } \\
\text { between objects }\end{array}$ & x $\Phi$ y & $\Phi \in \mathbf{R}$ & $\begin{array}{l}\mathrm{AB} / / \mathrm{CD} . \\
\mathrm{AB} \perp \mathrm{BC} . \\
\mathrm{AH} \text { bisector } \\
\quad \text { Angle(BAC). }\end{array}$ \\
\hline
\end{tabular}

Table 1: Kinds of facts

\footnotetext{
Specification of facts:

facts $\quad::=$ FACT: fact-def+

fact-def $\quad::=$ object-type $\mid$ attribute $\mid$ name $\mid$ relation

object-type $::=$ concept (name) |

concept (name, <name $>*$ )

relation $\quad::=$ relation $($ name, $<$ name $>+$ )

relation-def $::=$ RELATION name;

ARGUMENT: argument-def+

[facts]

ENDRELATION;
}

argument-def ::= name: type;

\subsection{Relational Network of Geometric objects}

Though the knowledge base of plane geometry in section 2.1, the relations between geometric objects in the figure of the geometric problems can be represented by the relational network. This network is built based on the combination between the structure of Rela-model and the conceptual graph $[5,7]$.

Definition 3.3: Relational network between geometric objects

Given a knowledge base of plane geometry $\mathrm{K}=(\mathbf{C}, \mathbf{R}$, Rules) as Rela-model, and a problem $\mathrm{P}=(\mathbf{O}, \mathbf{F}) \rightarrow \mathbf{G}$ as Def. 3.2. The relational network represents the relations between geometric objects in the problem $\mathrm{P}$ is a graph:

In which:

\section{(Vertex, Arc)}

- Vertex is a set of vertices of the graph. Each vertex is a geometric object. There are two kinds of objects:

* Primitive object: the object can be determined freedom or based on other objects.

* Deductive object: the object is implicitly determined if and only if its attributes are determined.

\section{Example 3.1:}

- An object of POINT-concept is primitive kind.

- An object of LINE-concept is primitive kind

- An object of ANGLE-concept is deductive kind because that object is determined if and only if its two rays are defined.

- An object of TRIANGLE-concept is deductive kind because that object is determined if and only if its three vertices are defined.

- Arc is a set of arcs representing the relations between objects. Those arcs is used to connect the vertices of the relational network. There are two kinds of arcs:

* Connection arc $(\longrightarrow)$ : Represents the connections between primitive objects.

* Implicitly arc $(\ldots \ldots . . \infty)$ : represents the connection with the deductive object.

Example 3.2: Given the triangle ABC. The relational network between geometric objects of triangle $\mathrm{ABC}$ is as Fig.1:

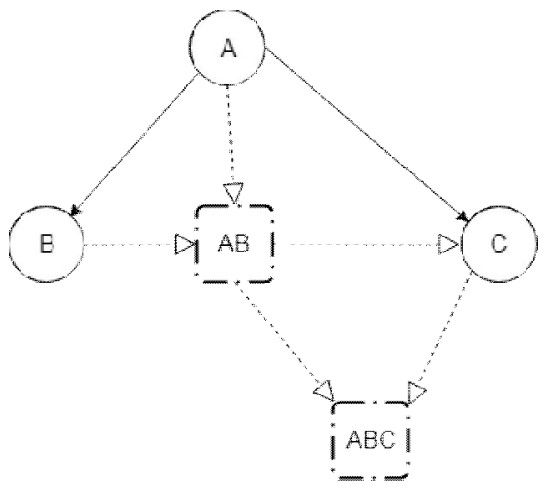

Figure 1: Relational network of triangle $\mathrm{ABC}$ 


\section{THE PROBLEM ABOUT AUTOMATIC DRAWING A FIGURE OF PLANE GEOMETY}

Given a knowledge base of plane geometry $\mathrm{K}=(\mathbf{C}, \mathbf{R}$, Rules $)$ as Rela-model, and the problem $\mathrm{P}=(\mathbf{O}, \mathbf{F}) \rightarrow$ Goal as Def. 3.2. There are two problems for drawing the figure of the problem $\mathrm{P}$.

- Problem 1: Build the relational network $G$ between geometric objects in the problem $\mathrm{P}$.

- Problem 2: Based on the relational network G, draw the figure of the problem $\mathrm{P}$.

\subsection{Algorithm for building the relational network}

Input: Knowledge base of plane geometry $\mathrm{K}=(\mathbf{C}, \mathbf{R}$, Rules), problem $\mathrm{P}=(\mathbf{O}, \mathbf{F}) \rightarrow$ Goal

Output: Relational network $\mathrm{G}$ represents geometric objects in the problem $\mathrm{P}$.

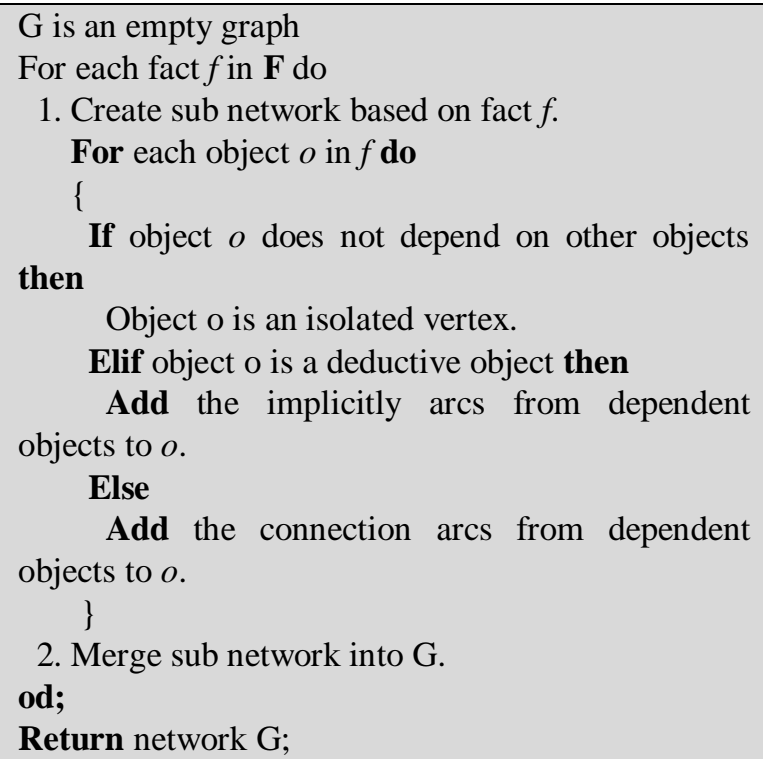

\subsection{Algorithm for drawing the figure of the problem}

Input: Problem $\mathrm{P}=(\mathbf{O}, \mathbf{F}) \rightarrow$ Goal of the knowledge domain about plane geometry $\mathrm{K}=(\mathbf{C}, \mathbf{R}$, Rules $)$,

Relational network $\mathrm{G}$ represents geometric objects in the problem $\mathrm{P}$.

Output: A figure of the problem $P$.

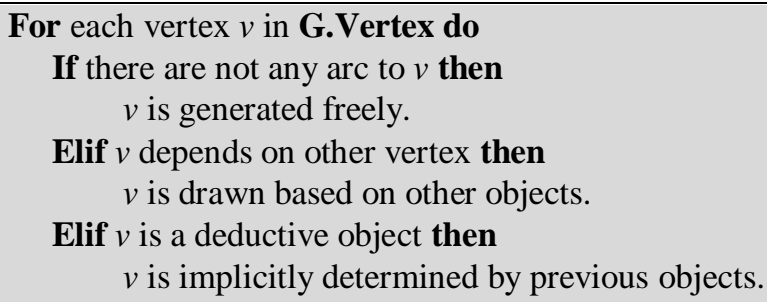

(All objects are determined by defining their coordinates or equations).

od;

Show the figure

\section{TESTING AND EXPERIMENTAL RESULTS}

\subsection{Testing}

Based on the knowledge domain about plane geometry in [15], a program for drawing the figure of geometric exercises has been set up and tested. This program can draw some kinds of geometric objects: Point, Line, Angle, Triangle and its other kinds, Quadrilateral and its other kinds, and Circle.

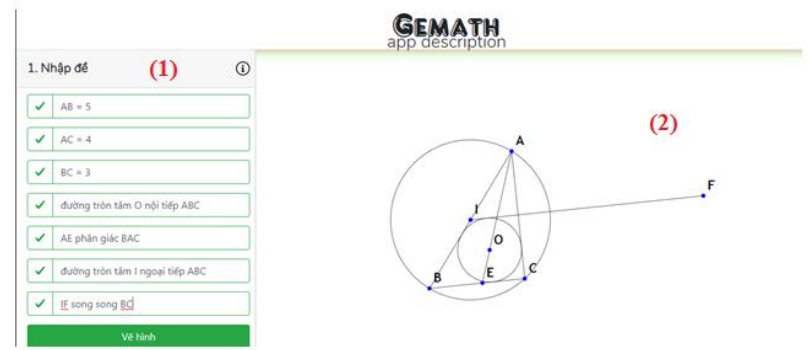

Figure 2: User-Interface of the program for drawing the figure of geometric exercises

(1) Input the hypothesis of the exercise

(2) The figure of the exercise which drawn by the program

Example 4.1: Given a triangle $\mathrm{ABC}$ and a circumscribed circle with center $\mathrm{O}$. The altitudes $\mathrm{AD}, \mathrm{BE}, \mathrm{CF}$ of $\mathrm{ABC}$ meet at $\mathrm{H}$ and intersect the circle $(\mathrm{O})$ at $\mathrm{M}, \mathrm{N}, \mathrm{P}$, respectively. Prove: AEHF is an inscribed quadrilateral.

$$
\begin{aligned}
& \text { Model of problem: } \\
& \mathbf{O}=\{\text { Triangle }(\mathrm{ABC}), \operatorname{Circle}(\mathrm{O}) \text {, } \\
& \text { D, E, F, H, M, N, P : Point }\} \\
& A D \text { altitudes Triangle(ABC), } \\
& \mathrm{BE} \text { altitudes Triangle( } \mathrm{ABC}) \text {, } \\
& \mathrm{CF} \text { altitudes Triangle(ABC), } \\
& \mathrm{H}=\mathrm{AD} \text { intersect } \mathrm{BE} \text {, } \\
& \mathrm{M}=\mathrm{AD} \text { intersect } \mathrm{Circle}(\mathrm{O}) \text {, } \\
& \mathrm{N}=\mathrm{BE} \text { intersect } \operatorname{Circle}(\mathrm{O}) \text {, } \\
& \mathrm{P}=\mathrm{CF} \text { intersect } \mathrm{Circle}(\mathrm{O})\}
\end{aligned}
$$$$
\mathbf{F}=\{\operatorname{Circle}(\mathrm{O}) \text { circumscribed Triangle }(\mathrm{ABC}),
$$$$
\text { Goal }=\{\text { Prove: } \text { Quadrilateral }(\text { AEHF }):
$$

InscribedQuadrilateral $\}$

The figure of this problem has been drawn by the program as Fig. 3:

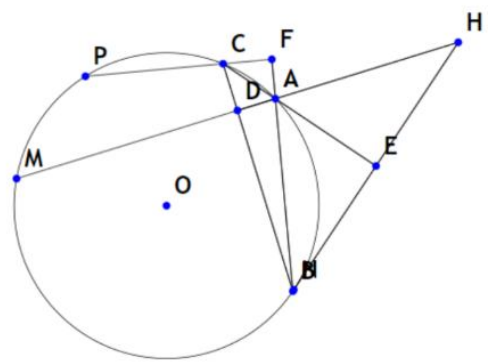

Figure 3: The figure of the example 4.1

Example 4.2: Given a parallelogram $\mathrm{ABCD}, \mathrm{AB}=7$, $\mathrm{AD}=9$, and $\mathrm{O}$ is the intersection point of $\mathrm{AC}$ and $\mathrm{BD}$. Let $\mathrm{OI}$ be the bisector of $\angle \mathrm{DOC}$ with I belongs to $\mathrm{DC}$. Let $\mathrm{M}$ be the intersection point of $\mathrm{AI}$ and $\mathrm{BD}, \mathrm{N}$ be the intersection point of 
$\mathrm{BI}$ and $\mathrm{AC}$. The line $\mathrm{MN}$ meets $\mathrm{AD}, \mathrm{BC}, \mathrm{CD}$ at $\mathrm{J}, \mathrm{K}, \mathrm{L}$ respectively.

Prove: $\mathrm{AI}$ is the bisector of $\angle \mathrm{DAC}$

Model of problem:

$\mathbf{O}=\{$ Parallelogram $(\mathrm{ABCD})$,

O, I, M, N, J, K, L: Point $\}$

$\mathbf{F}=\{\mathrm{AB}=7, \mathrm{AD}=9$,

$\mathrm{O}=\mathrm{AD}$ intersect $\mathrm{BC}$,

I belongs $\mathrm{DC}$, OI bisector $\angle \mathrm{DOC}$,

$\mathrm{M}=\mathrm{AI}$ intersect $\mathrm{BD}, \mathrm{N}=\mathrm{BI}$ intersect $\mathrm{AC}$,

$\mathrm{J}=\operatorname{line}(\mathrm{MN})$ intersect $\mathrm{AD}$,

$\mathrm{K}=$ line $(\mathrm{MN})$ intersect $\mathrm{BC}$,

$\mathrm{L}=$ line $(\mathrm{MN})$ intersect line $(\mathrm{CD})\}$

Goal $=\{$ Prove: AI bisector $\angle \mathrm{DAC}\}$

The figure of this problem has been drawn by the program as Fig. 4:

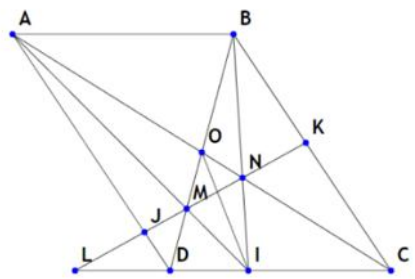

Figure 4: The figure of the example 4.2

\subsection{Results of testing}

The exercises for testing is collected from books [15]. Those problems are classified by grades from $6^{\text {th }}-9^{\text {th }}$ :

- $6^{\text {th }}$ grade: The problems are about geometric objects: line, segment, ray, angle and their relations.

- $7^{\text {th }}$ grade: Besides geometric objects in the $6^{\text {th }}-$ grade, the problems are about: triangle and their properties: altitude, bisector, etc.

- $8^{\text {th }}$ grade: Besides the knowledge of triangle, the problems are about: quadrilateral and their properties, kinds of quadrilateral: parallelogram, rhombus, rectangle, square, etc.

- $9^{\text {th }}$ grade: Besides the knowledge of triangle and quadrilateral, the problems are about: circle and their properties, kinds of circle: circumscribed circle, inscribed circle, escribed circle.

Table 2: Results of testing the drawing of the figure

\begin{tabular}{|c|c|c|c|}
\hline Grade & $\begin{array}{c}\text { Number of } \\
\text { testing problems }\end{array}$ & $\begin{array}{c}\text { Number of } \\
\text { correct problems }\end{array}$ & Proportion \\
\hline $6^{\text {th }}$ grade & 12 & 8 & $67 \%$ \\
\hline $7^{\text {th }}$ grade & 16 & 9 & $56 \%$ \\
\hline $8^{\text {th }}$ grade & 16 & 14 & $88 \%$ \\
\hline $9^{\text {th }}$ grade & 15 & 12 & $80 \%$ \\
\hline Total & $\mathbf{5 9}$ & $\mathbf{4 3}$ & $\mathbf{7 3 \%}$ \\
\hline
\end{tabular}

In $6^{\text {th }}$ and $7^{\text {th }}$ grades, geometric objects in problems are not closely interrelated. The problems only have single inquires for each object, so they are not enough data for drawing them exactly. In contrast, in $8^{\text {th }}$ and $9^{\text {th }}$ grades, the relations between geometric objects in problems are closely. Hence, the program can determine them clearly for automatic drawing. However, some problems have the complex relations between objects, so the program have not yet drawn them.

\section{CONCLUSION}

The figure is an essential factor in the geometric problems. Based on the knowledge model of relations, Rela-model, a relational network between geometric objects is given. This network is a semantic network representing the relationships between objects in a geometric problem. Using the network, algorithms for automatically drawing the figure of the problem are proposed. The program can draw almost basic geometric objects in middle-school, such as point, line, triangle, Quadrilateral, circle. The figure generating by this program is natural, precise and similar the figure drawn manually.

In the future, the program for automatically drawing the figure of a problem will be combined to the Intelligent Problem Solver in plane geometry $[2,3]$. This combination makes the IPS more completely when it can give the solution and the figure of the geometric problem, and that IPS can meet the requirements of an IPS in education [16]. Moreover, the method for drawing the figure can be studied to apply for drawing the figure of a problem in solid geometry [5, 14].

\section{REFERENCES}

1. D. Nhon. Intelligent Problem Solvers in Education: Design Method and Applications, in Intelligent systems, V. Koleshko, Ed., InTech, 2012, ch.6.

2. N. Do, H. Nguyen. A Reasoning method on Knowledge Base of Computational Objects and Designing a System for automatically solving plane geometry problems, in Proceedings of World Congress on Engineering and Computer Science 2011, San Francisco, USA, 2011, pp. 294-299.

3. H.D. Nguyen, V.T. Pham, T.T. Le, D.H. Tran. A Mathematical Approach for Representation Knowledge about Relations and Its Application, in Proceedings of 2015 IEEE International Conference on Knowledge and Systems Engineering (KSE 2015), Ho Chi Minh, Vietnam, 2015, pp. 324-327. https://doi.org/10.1109/KSE.2015.78

4. I. Hatzilygeroudis, J. Prentzas. Knowledge Representation Requirements for Intelligent Tutoring Systems, in Proceedings of $7^{\text {th }}$ International Conference on Intelligent Tutoring Systems (ITS 2004), LNCS 3220, pp.87-97, Springer, 2004. https://doi.org/10.1007/978-3-540-30139-4_9

5. N.V. Do, H.D. Nguyen, A. Selamat. Knowledge-Based model of Expert Systems using Rela-model. International Journal of Software Engineering and Knowledge Engineering (IJSEKE), Vol. 28, No. 8, pp. 1047 - 1090, 2018.

https://doi.org/10.1142/S0218194018500304 
6. J.F. Sowa, A. Borgida. Principles of Semantic Networks: Explorations in the Representation of Knowledge, Morgan Kaufmann, 1991.

7. H.D. Nguyen, V.T. Pham. Relational Network of Geometric Objects and Apply to Draw the Figure of Problem automatically, Journal of Science, Special Issue, Can Tho University, pp. 198-204, 2013.

8. H. Nguyen, C. Sakama, T. Sato, K. Inoue. Computing Logic Programming Semantics in Linear Algebra, in Proceedings of 12th Multi-disciplinary International Conference on Artificial Intelligence (MIWAI 2018), Ha Noi, Vietnam, 2018, LNAI 11248, Springer, pp. 32-48. https://doi.org/10.1007/978-3-030-03014-8_3

9. GeoGebra: https://www.geogebra.org/geometry

10. M. Hohenwarter, Z. Kovács, and T. Recio. Using Automated Reasoning Tools to Explore Geometric Statements and Conjectures, in Proof Technology in Mathematics Research and Teaching, G. Hanna, D.A.Reid, M. Villiers, Eds., Springer, 2019, pp.215-236. https://doi.org/10.1007/978-3-030-28483-1_10

11. F. Botana, Z. Kovács, A. Martínez-Sevilla, and T.Recio. Automatically Augmented Reality with GeoGebra, in Augmented Reality in Educational Settings, T. Prodromou, Eds., Brill, 2019, pp. 347-368. https://doi.org/10.1163/9789004408845_015

12. C. Kimberling. Geometry in Action: A Discovery Approach Using The Geometer's Sketchpad, Key College Publishing, Emeryville, California, USA, 2003.

13. Geometer Sketchpad: https://www.dynamicgeometry.com/

14. H. Nguyen, D. Nguyen, V. Pham. Design an Intelligent Problems Solver about Solid Geometry based on Knowledge model about Relation, in Proceedings of 2016 IEEE International Conference on Knowledge and Systems Engineering (KSE 2016), Ha Noi, Vietnam, 2016, pp. $150-155$ https://doi.org/10.1109/KSE.2016.7758045

15. Vietnam Ministry of Education and Training. Textbook and workbook of plane geometry in middle school, Publisher of Education, 2014.

16. H.D. Nguyen, N.V. Do, N.P. Tran, X.H. Pham, V.T. Pham. Some criteria of the Knowledge Representation method for an Intelligent Problem Solver in STEM education. Applied Computational Intelligence and Soft Computing, accepted, 2020, in press. 